Supporting Information

\title{
Novel inorganic integrated membrane electrodes for membrane capacitive deionization
}

Qinghao $\mathrm{Wu}^{\mathrm{a}}$, Dawei Liang ${ }^{\mathrm{a}, *}$, Shanfu Lu $u^{\mathrm{a}}$, Jin Zhang ${ }^{\mathrm{a}}$, Haining Wang ${ }^{\mathrm{a}}$, Yan Xiang ${ }^{\mathrm{a}, *}$, and Doron Aurbach ${ }^{\mathrm{b}}$

a Beijing Key Laboratory of Bio-inspired Energy Materials and Devices, School of Space and Environment, Beihang University, Beijing, 102206, PR China

${ }^{\mathrm{b}}$ Department of Chemistry, Bar-Ilan University, Ramat-Gan, 5290002, Israel

*Corresponding author: liangdw@buaa.edu.cn, xiangy@buaa.edu.cn 

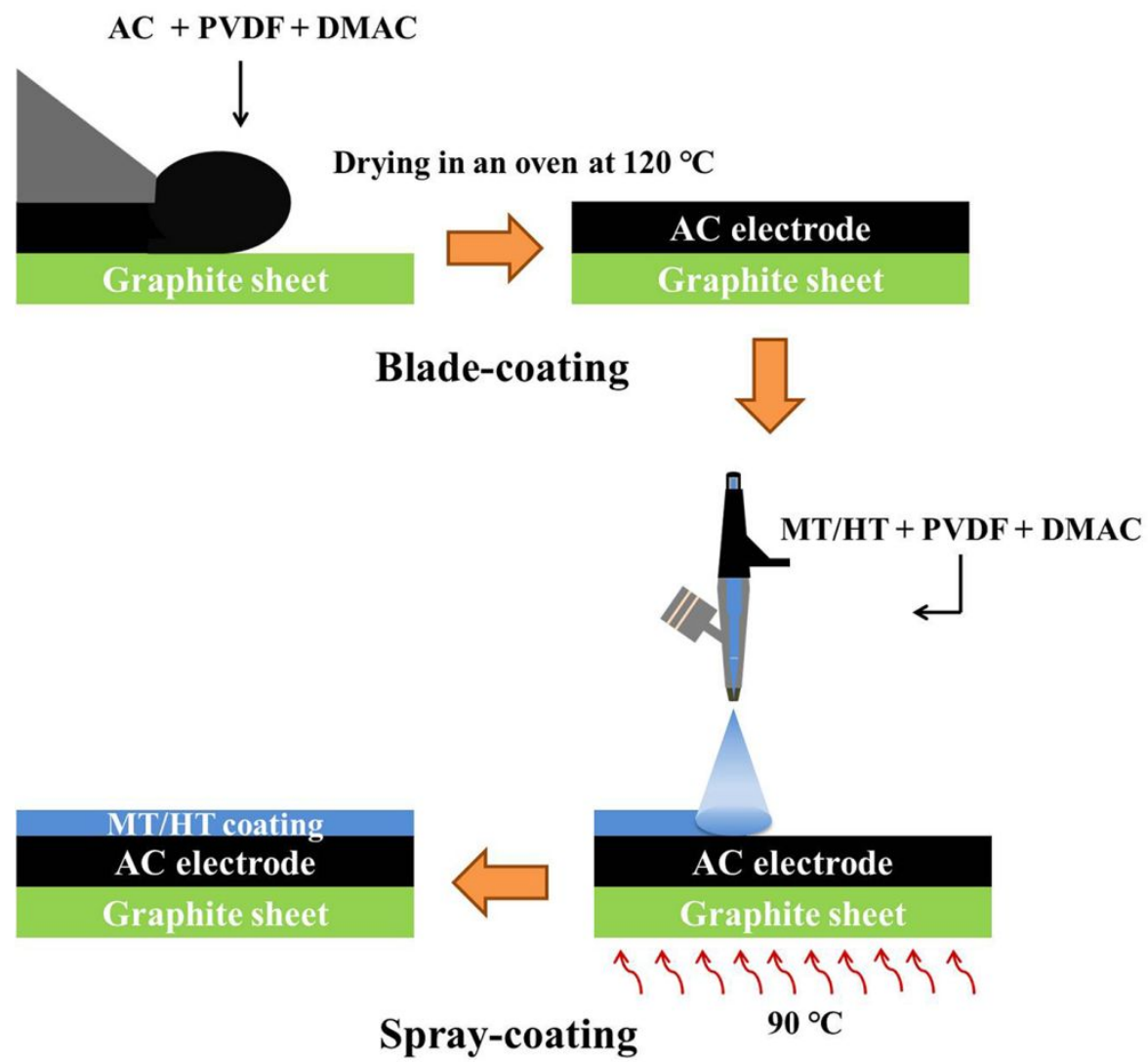

Figure S1. Schematic diagram of the preparation of ion-exchange inorganics-coated electrode. 
(a)

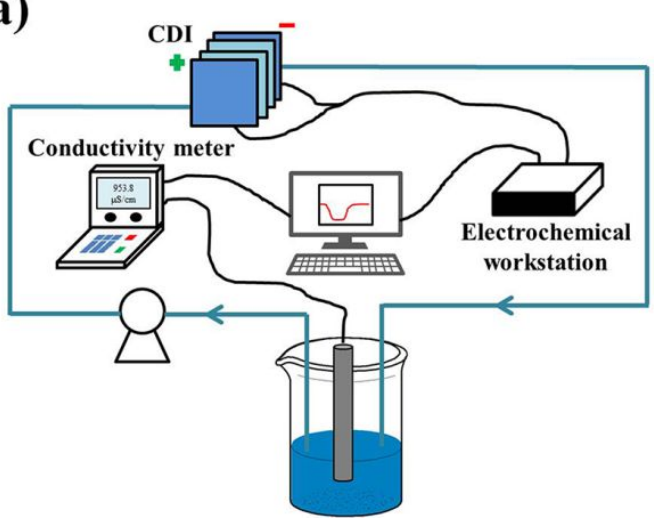

(b)

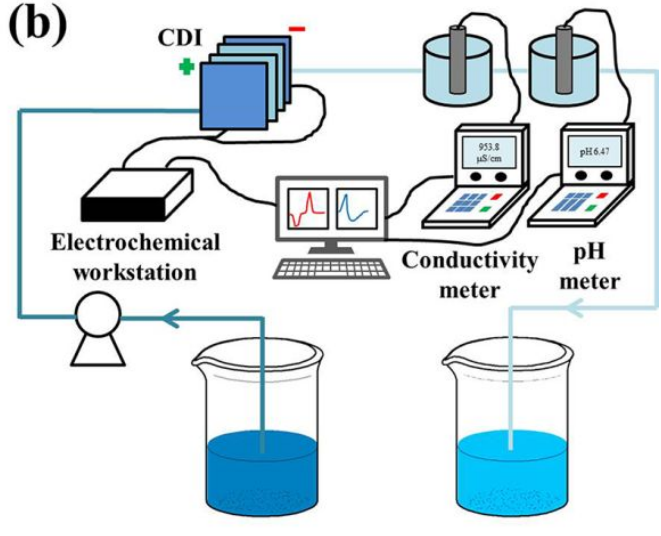

Figure S2. Schematic diagrams of (a) batch mode and (b) single-pass mode. 


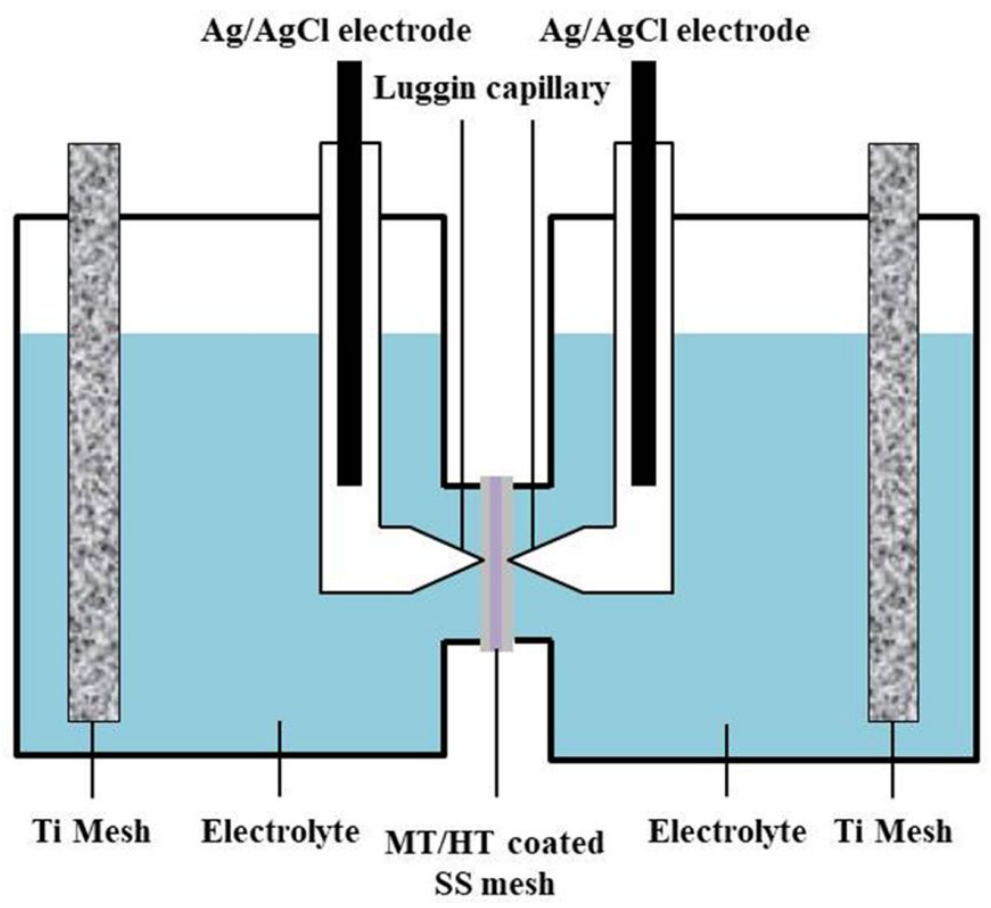

Figure S3. Schematic diagram of four-electrode electrochemical system used in testing chronopotentiometry curve. 


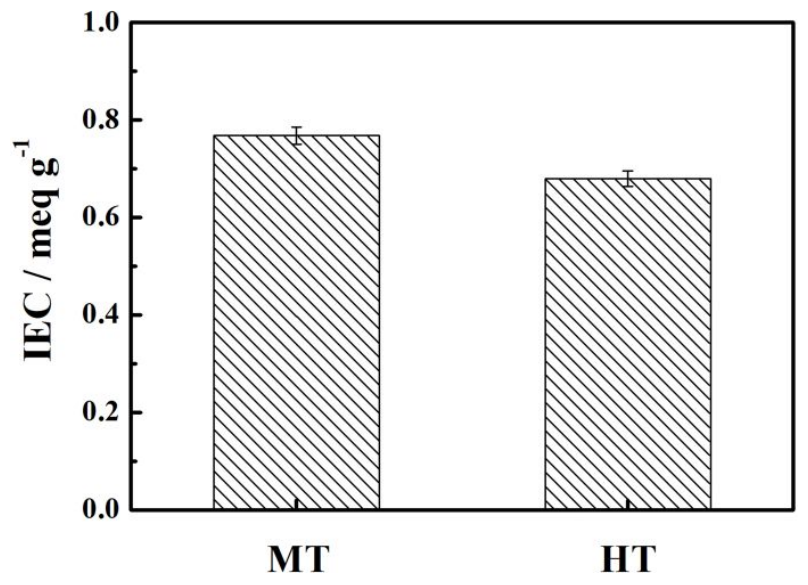

Figure S4. Ion-exchange capacities of montmorillonite (MT) and hydrotalcite (HT). 

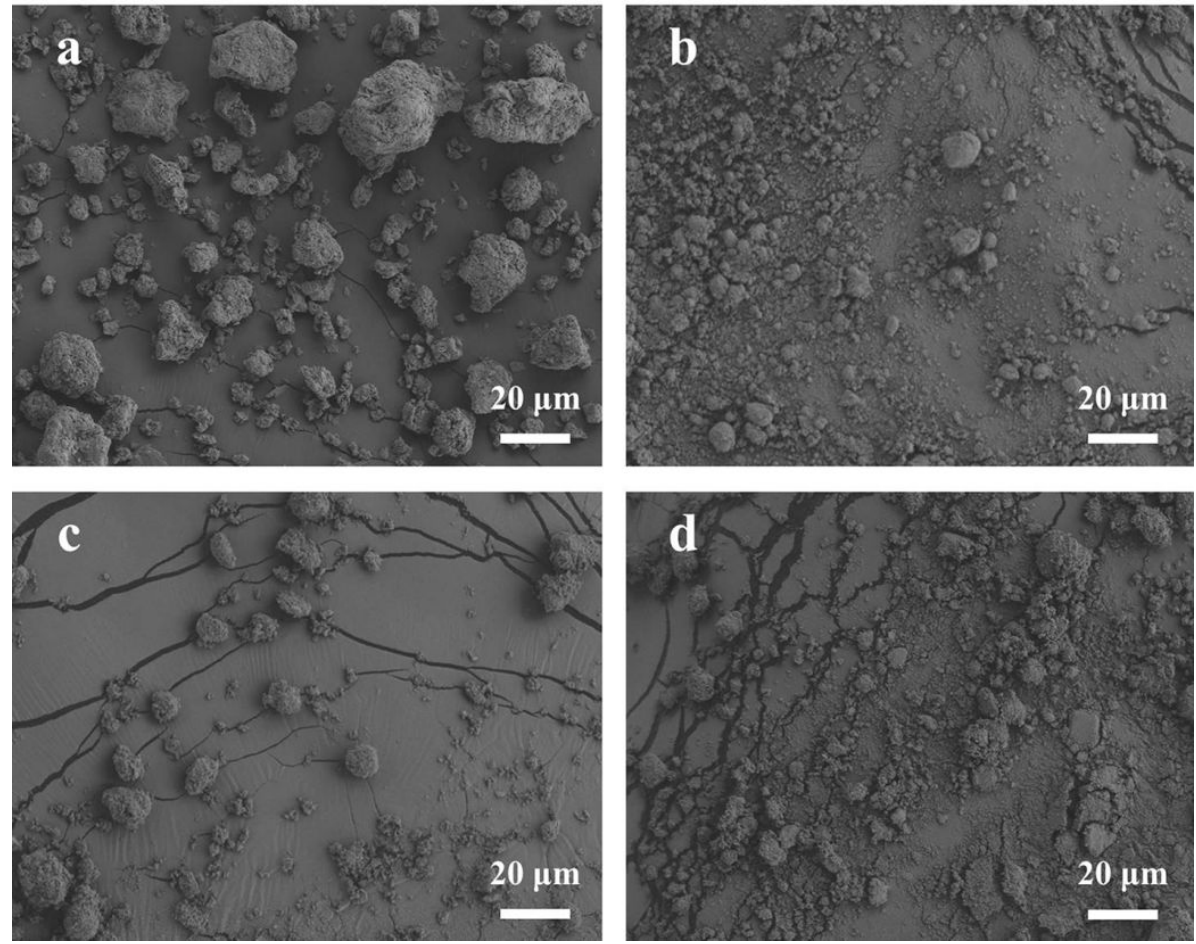

Figure S5. SEM images of (a, b) MT and (c, d) HT powders (a, c) before and (b. d) after ball-milling.
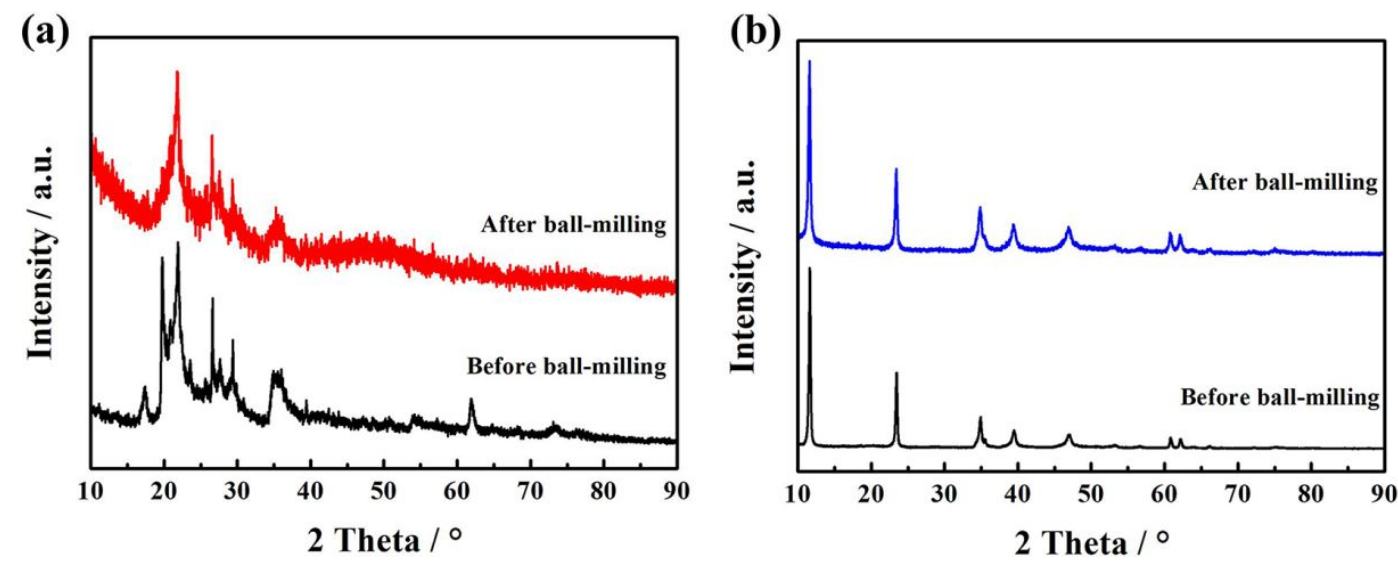

Figure S6. X-ray diffraction (XRD) patterns of (a) MT and (b) HT powders before and after ball-milling. 


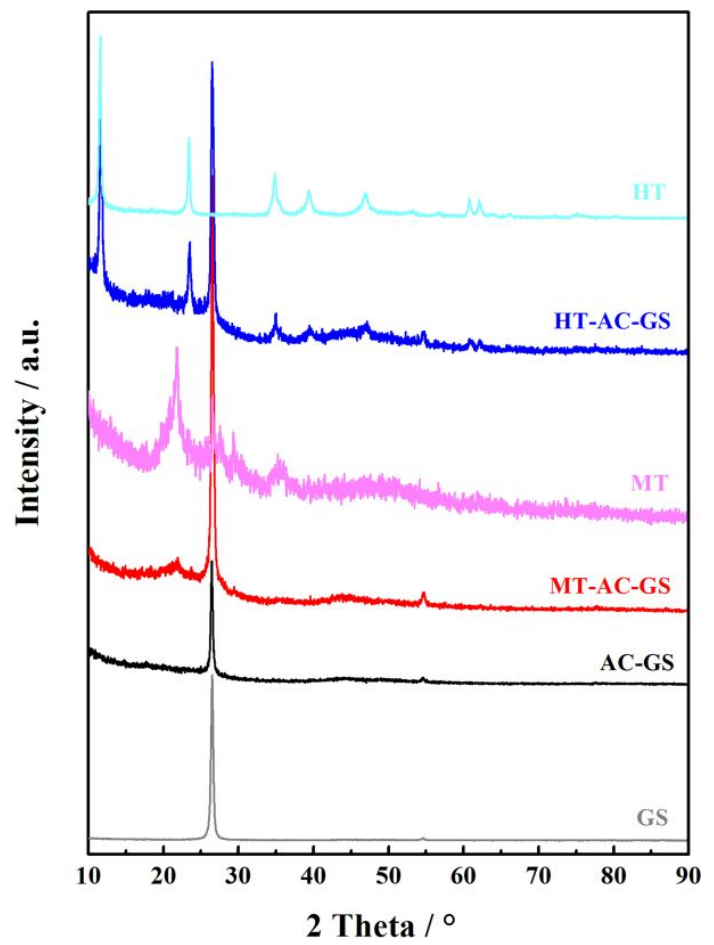

Figure S7. XRD patterns of MT-AC and HT-AC electrodes. 


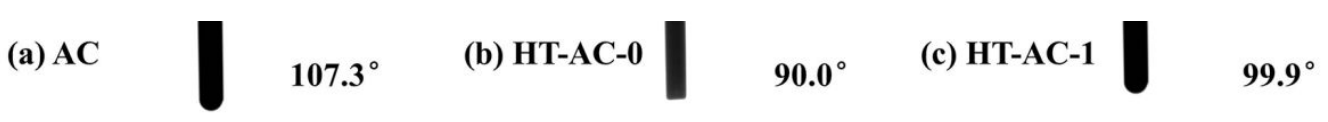

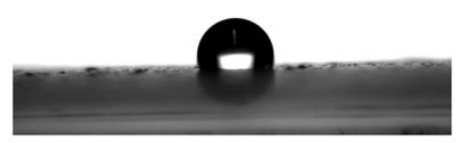

(d) HT-AC-2 $135.0^{\circ}$

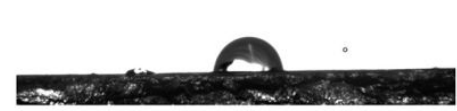

(e) HT-AC-3

$118.4^{\circ}$

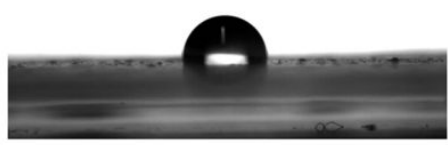

(f) PVDF-AC

$89.9^{\circ}$
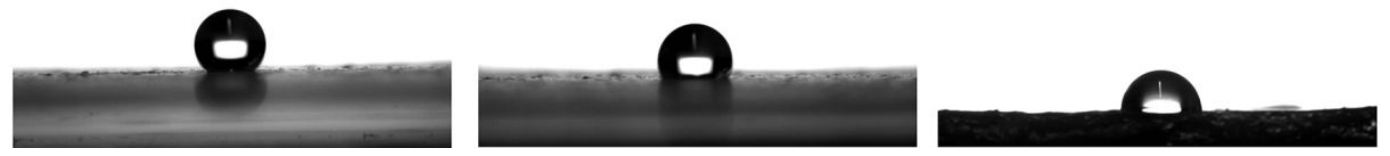

Figure S8. Images of water contact angles on the surfaces of (a) AC, (b) HT-AC-0, (c) HT-AC-1, (d) HT-AC-2, (e) HT-AC-3, and (f) PVDF-AC electrodes. (HT-AC-0: HT/PVDF=1:0, PVDF-AC: HT/PVDF=0:1)
(a) MT-AC-0
$23.0^{\circ}$
(b) MT-AC-1
$60.7^{\circ}$
(c) MT-AC-2
$88.5^{\circ}$

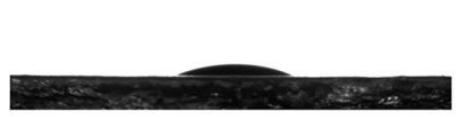

(d) MT-AC-3

$120.6^{\circ}$
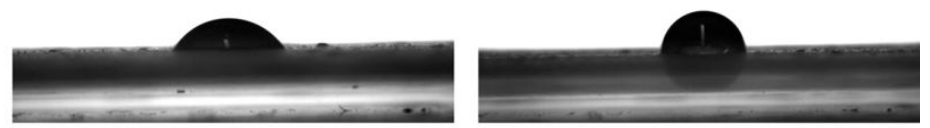

(e) MT-AC-4

$89.3^{\circ}$

(f) PVDF-AC

$89.2^{\circ}$
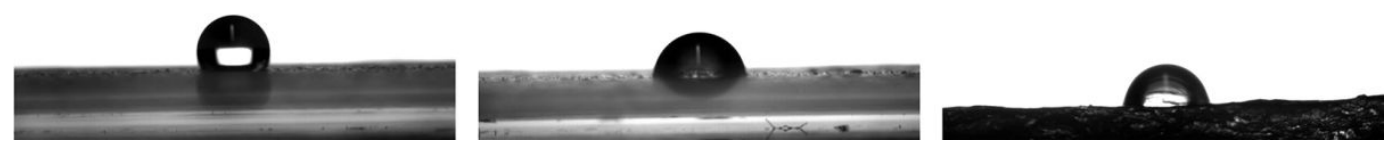

Figure S9. Images of water contact angles on the surfaces of (a) MT-AC-0, (b) MT-AC-1, (c) MT-AC-2, (d) MT-AC-3, (e) MT-AC-4, and (f) PVDF-AC electrodes. (MT-AC-0: MT/PVDF=1:0, PVDF-AC: MT/PVDF=0:1) 

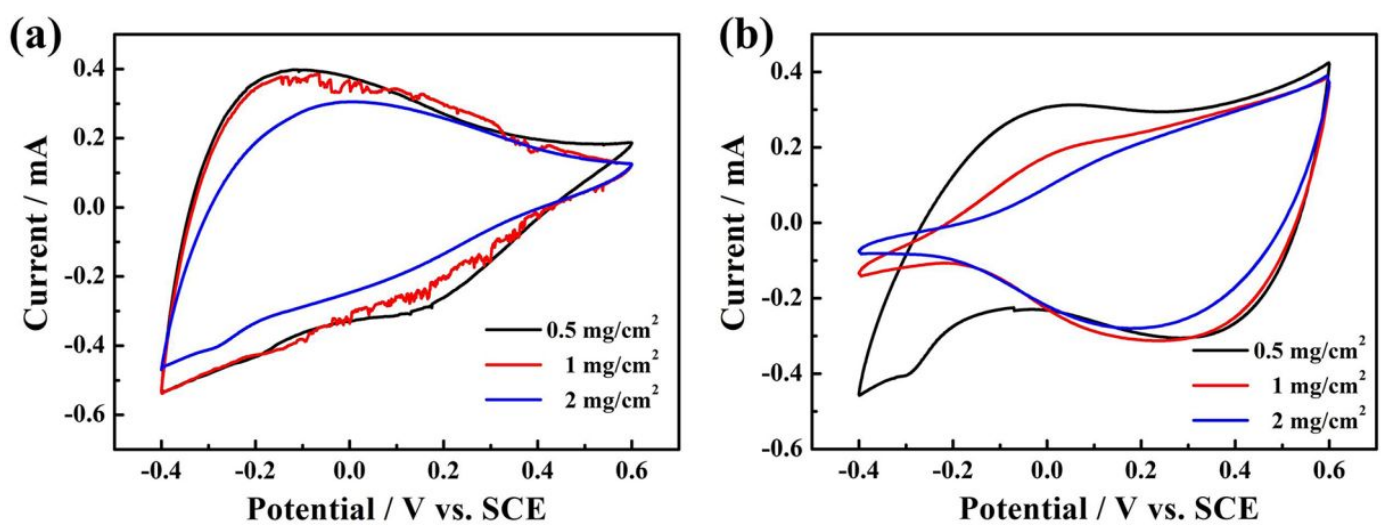

Figure S10. CV curves of (a) MT-AC-3 and (b) HT-AC-2 electrodes with coating at different mass loadings of ion-exchange material in $2 \mathrm{~g} \mathrm{~L}^{-1} \mathrm{NaCl}$ at $1 \mathrm{mV} \mathrm{s}^{-1}$. 

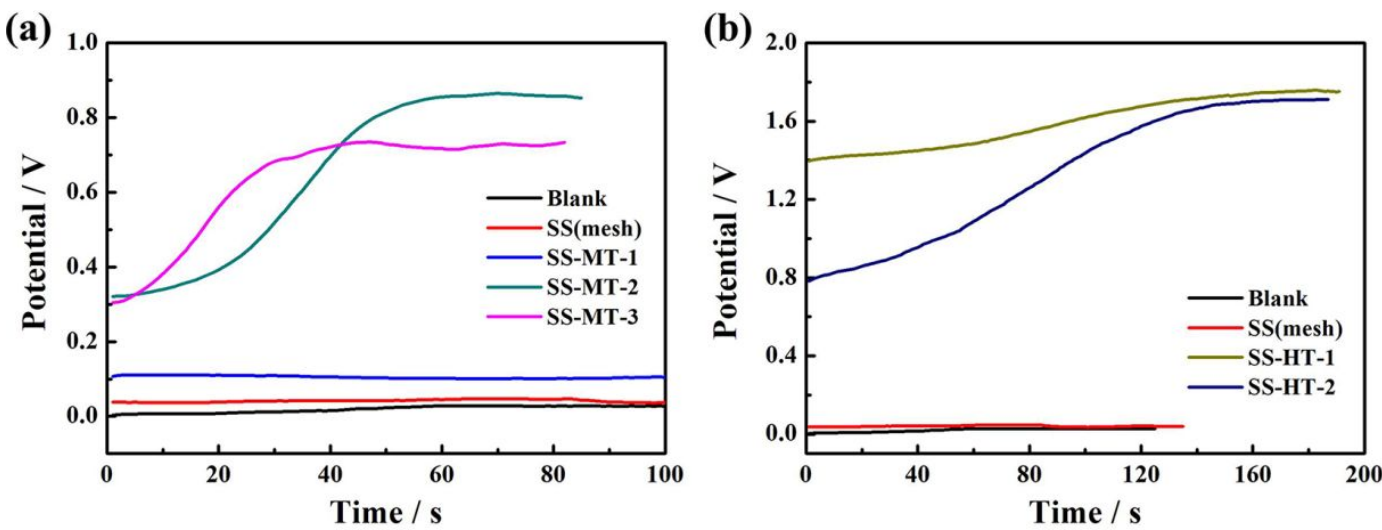

Figure S11. Chronopotentiometric curves of (a) MT and (b) HT coatings measured in the four-electrode system at a constant current density $20 \mathrm{~mA} \mathrm{~cm}-2$.

(a)

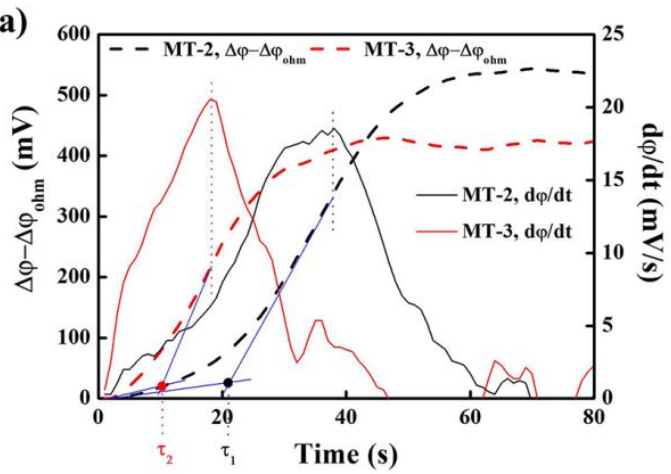

(b)

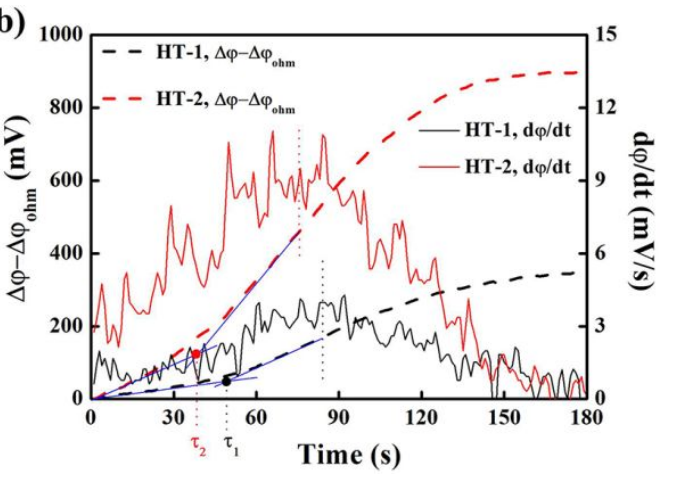

Figure S12. Chronopotentiometric curves and their derivatives of (a) MT and (b) HT coatings to obtain transition times at intersection point. 

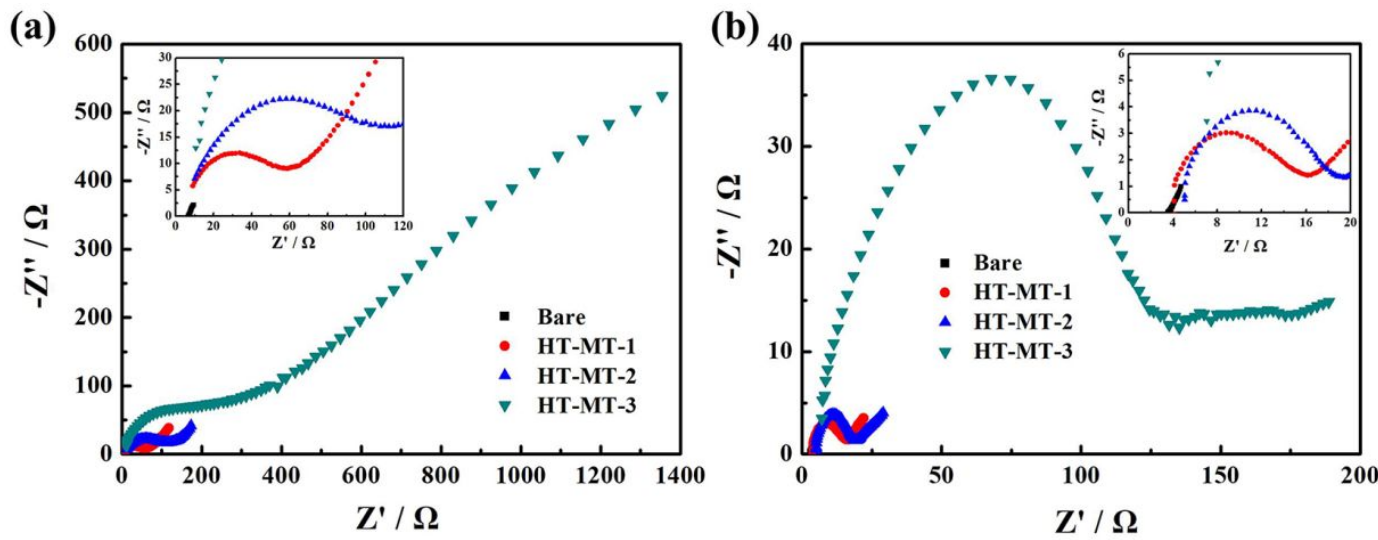

Figure S13. Electrochemical impedance spectroscopy of the assembled CDI and MCDI systems measured from $100 \mathrm{k}-0.1 \mathrm{~Hz}$ at $0 \mathrm{~V}$ (a) before and (b) after testing. Inset: corresponding enlarged views in the high-frequency region. 

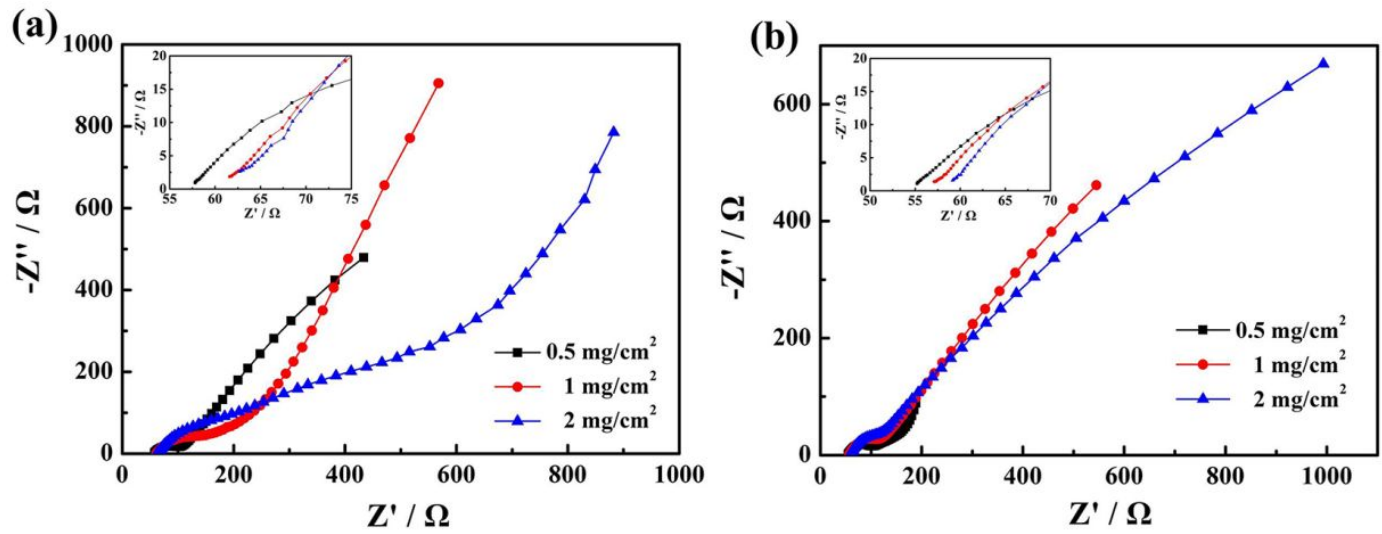

Figure S14. Electrochemical impedance spectroscopy of (a) MT-AC-3 and (b) HT-AC-2 electrodes with different mass loading of ion-exchange material measured from $10 \mathrm{k}-0.01 \mathrm{~Hz}$ at open circuit potential. Inset: corresponding enlarged views in the high-frequency region. 
(a)

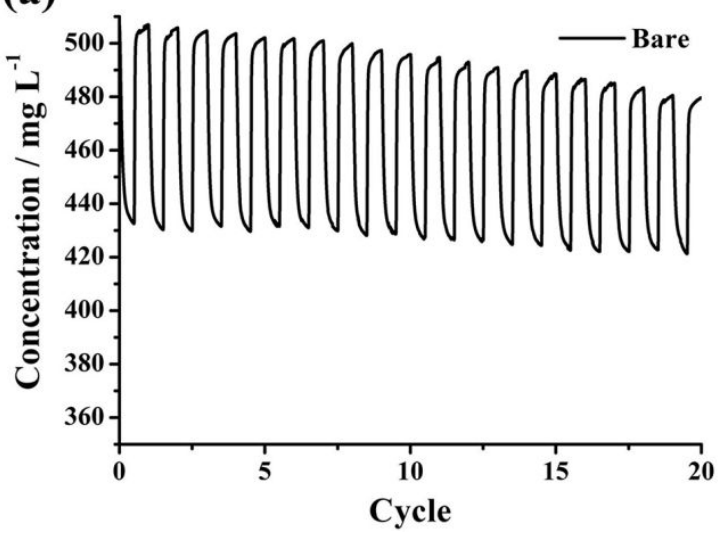

(b)

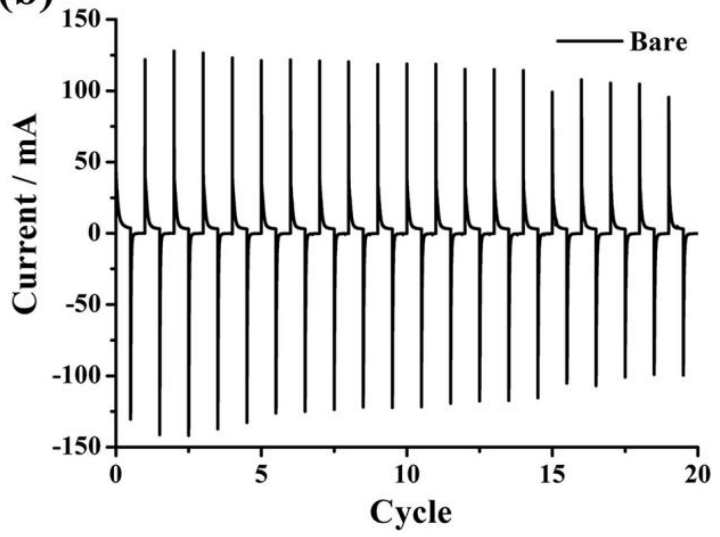

Figure S15. (a) Concentration variation and (b) charging/discharging current of the traditional CDI (bare) system employing AC electrodes in the batch mode.
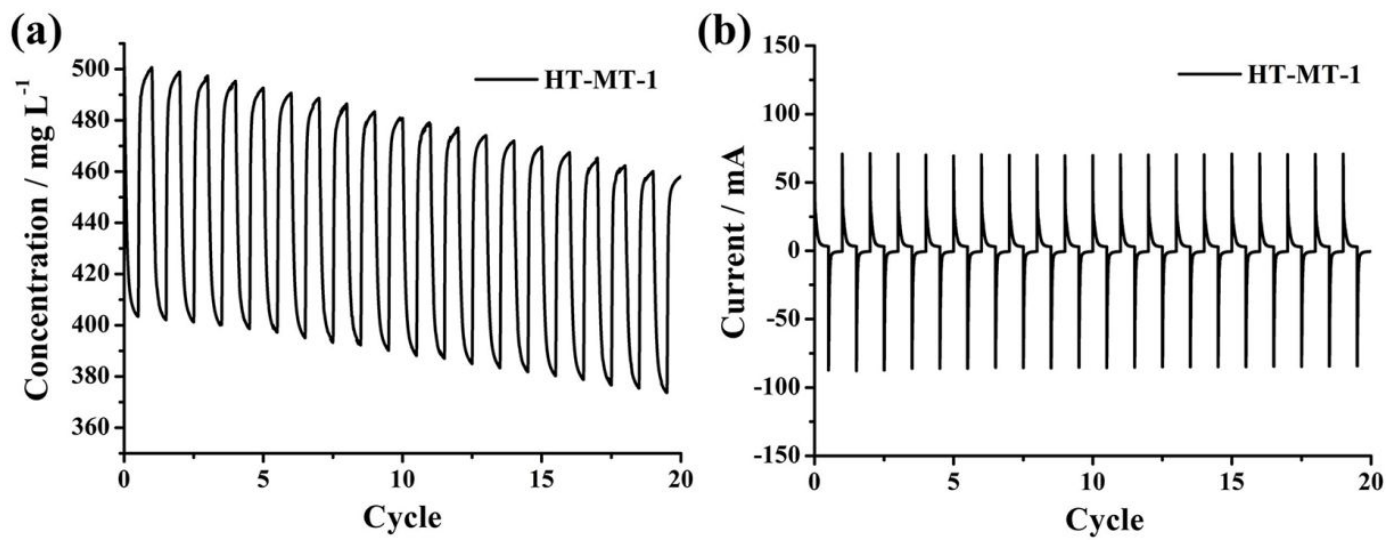

Figure S16. (a) Concentration variation and (b) charging/discharging current of HT-MT-1 system in the batch mode.
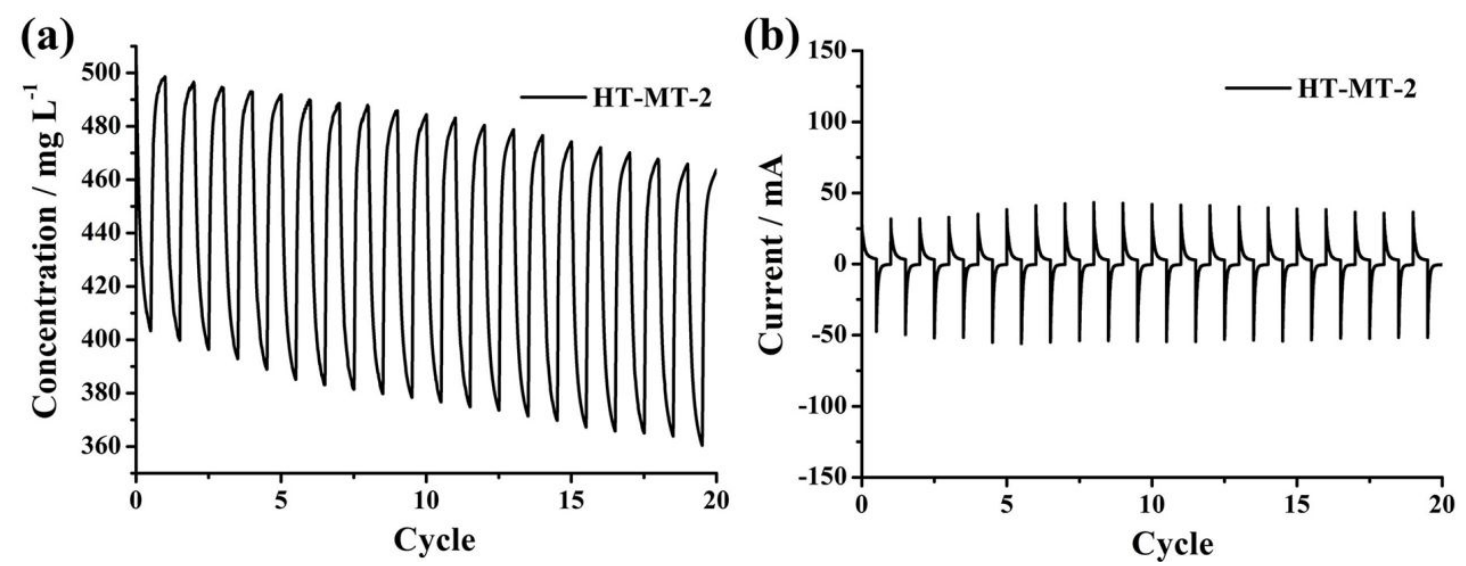

Figure S17. (a) Concentration variation and (b) charging/discharging current of HT-MT-2 system in the batch mode. 

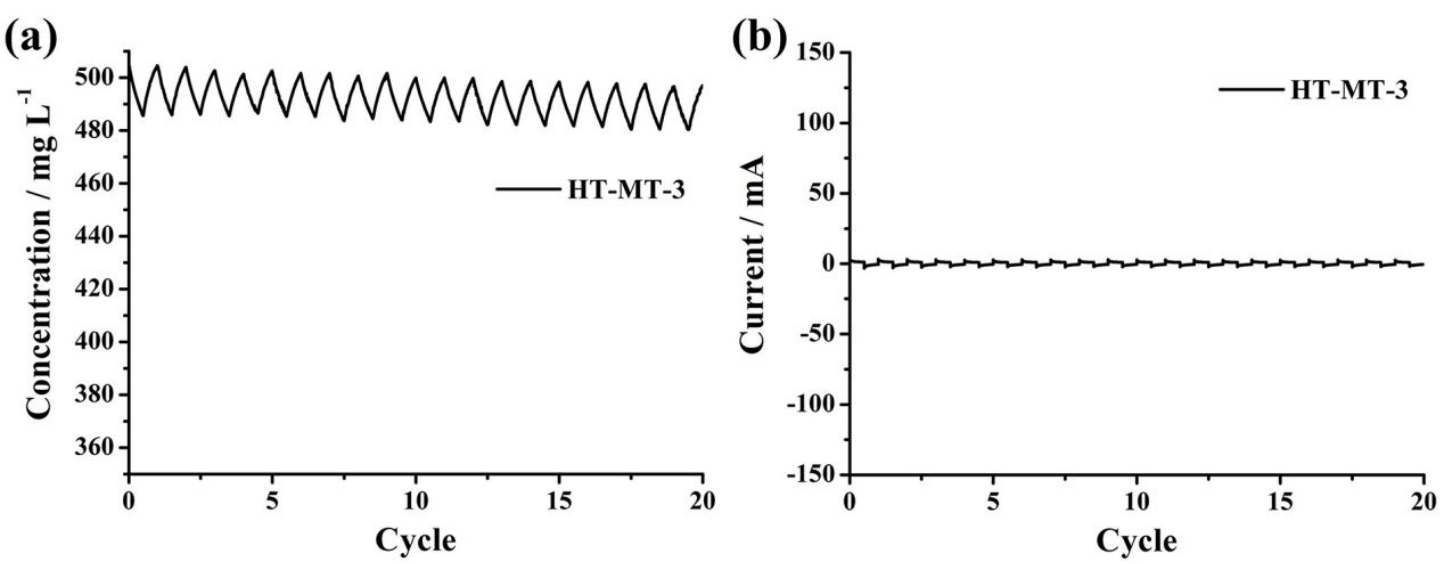

Figure S18. (a) Concentration variation and (b) charging/discharging current of HT-MT-3 system in the batch mode.

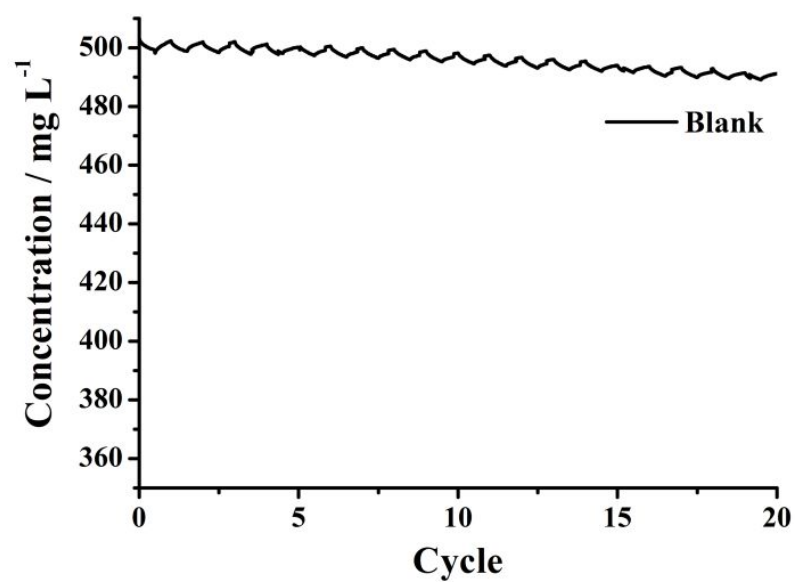

Figure S19. Concentration variation of the assembled CDI system employing graphite sheets in the batch mode. 

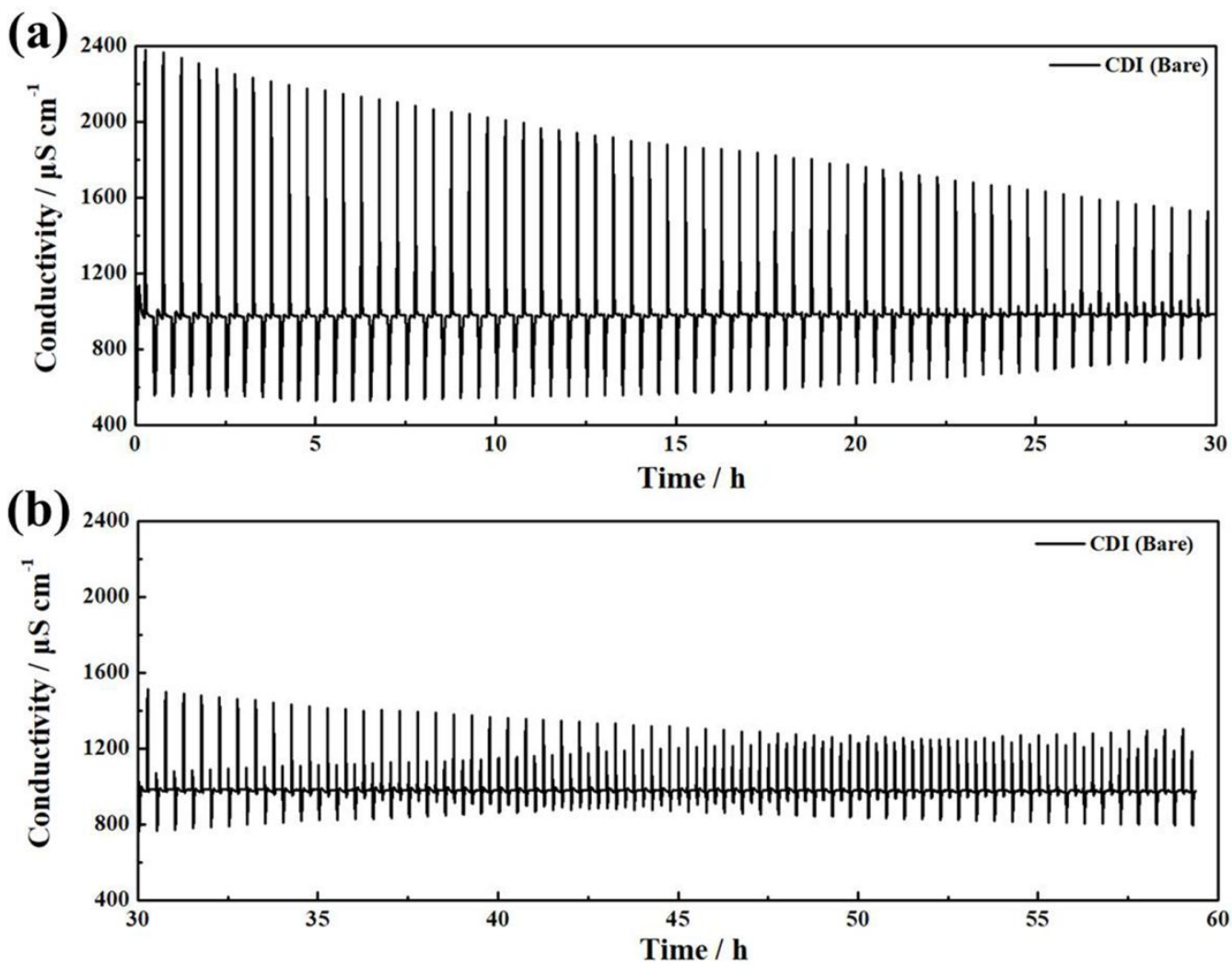

Figure S20. Conductivity profiles of traditional CDI (bare) system in the single-pass mode: (a) 0-30 h, (b) 30-60 h. 
(a)

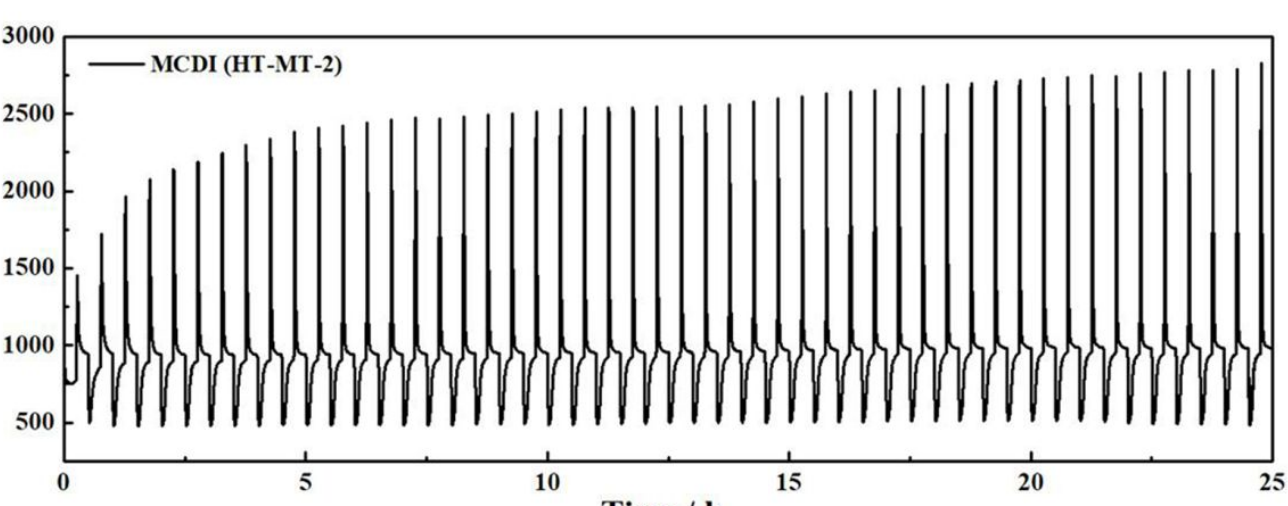

(b) 30

Time / h

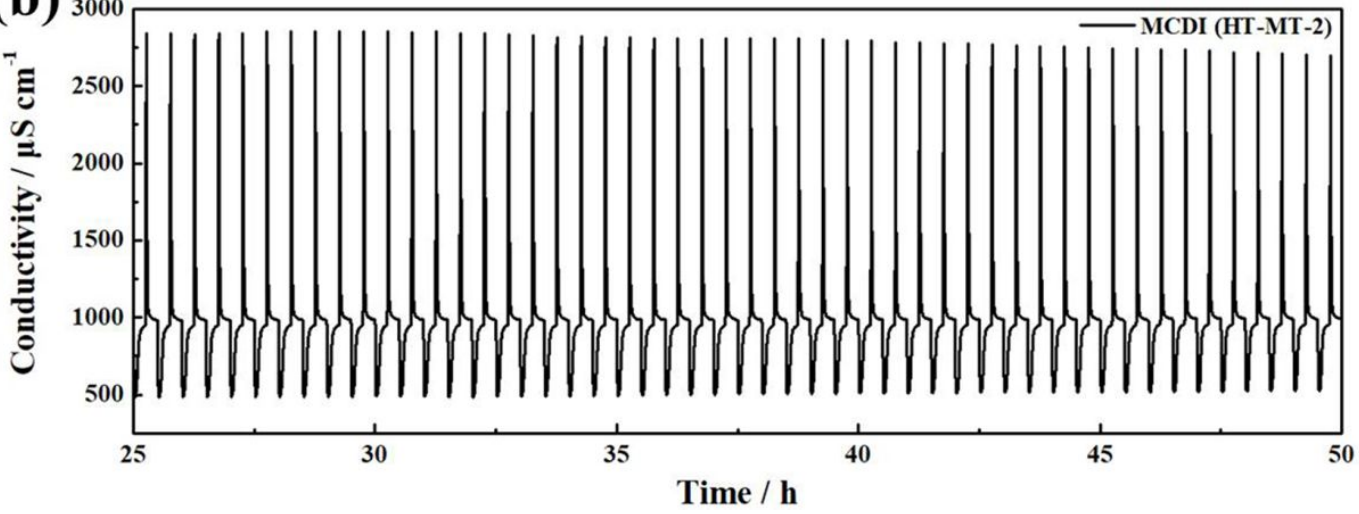

Figure S21. Conductivity profiles of HT-MT-2 system in the single-pass mode: (a) 0-25 h, (b) 25-50 h. 
(a)
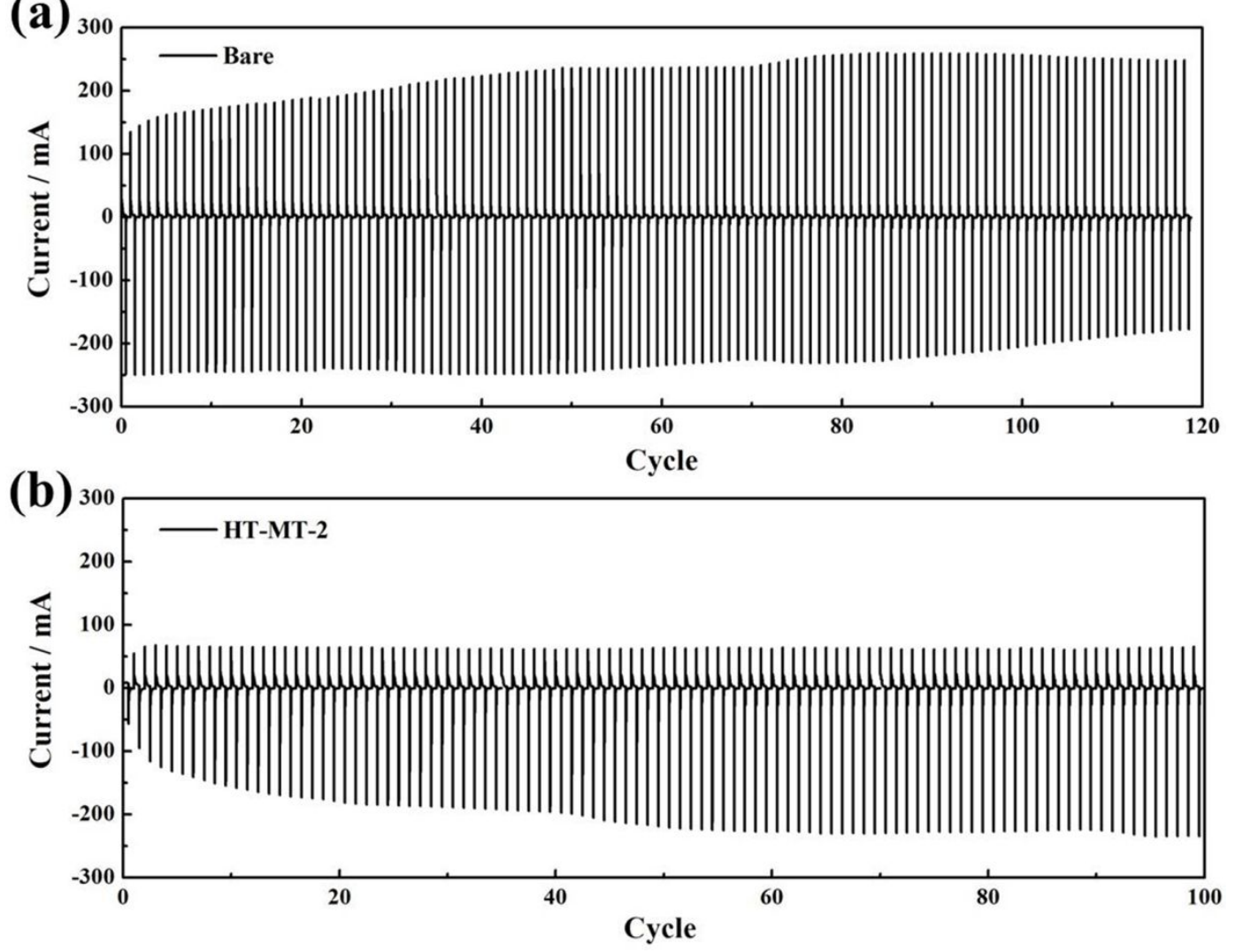

Figure S22. Charging and discharging currents of (a) the traditional CDI (bare) and (b) HT-MT-2 systems in the single-pass mode. 
Table S1. Content of C, O, and F (in at.\%) in the bare AC electrodes as obtained by X-ray photoelectron spectroscopy (XPS)

\begin{tabular}{llll}
\hline & $\mathrm{C}$ & $\mathrm{O}$ & $\mathrm{F}$ \\
\hline Pristine electrode & 74.4 & 7.5 & 18.1 \\
Negatively polarized electrode & 69.2 & 9.2 & 21.6 \\
Positively polarized electrode & 64.9 & 14.1 & 21.0 \\
\hline
\end{tabular}

(a)

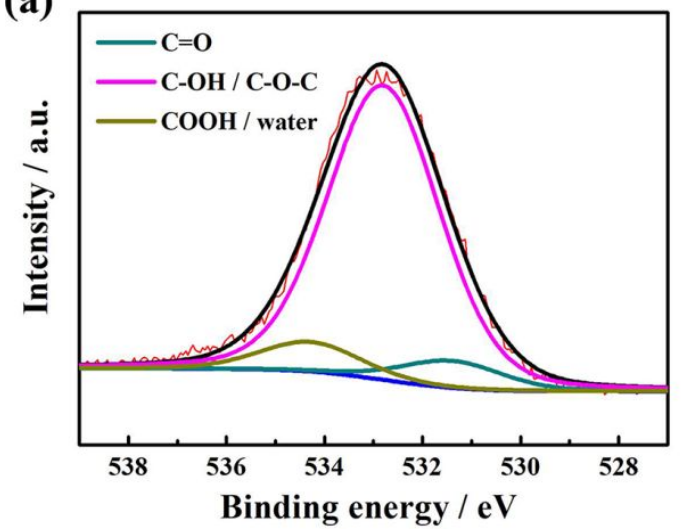

(b)

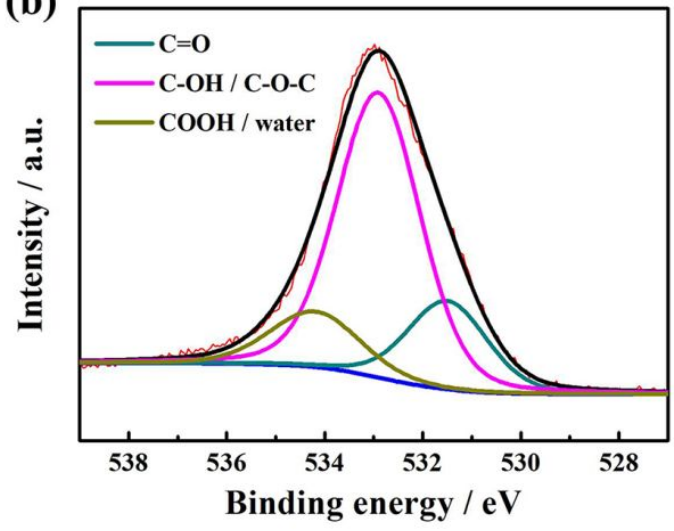

Figure S23. High-resolution O 1s XPS spectra of (a) pristine electrode and (b) positively polarized electrode (b). 

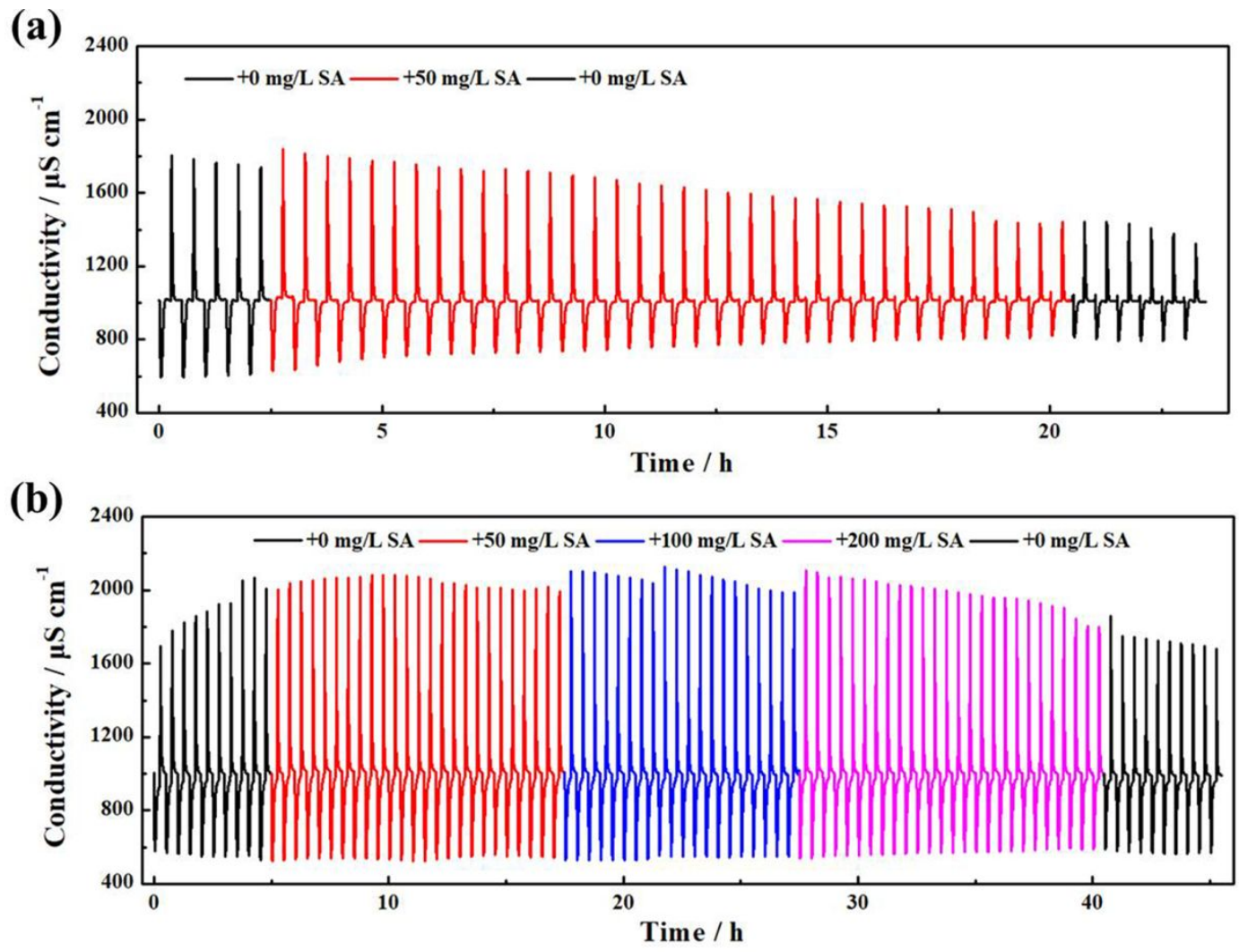

Figure S24. Conductivity profiles of (a) the traditional CDI (bare) and (b) HT-MT-2 systems in $500 \mathrm{mg} \mathrm{L}^{-1} \mathrm{NaCl}$ with the addition of SA of $50-200 \mathrm{mg} \mathrm{L}^{-1}$. 

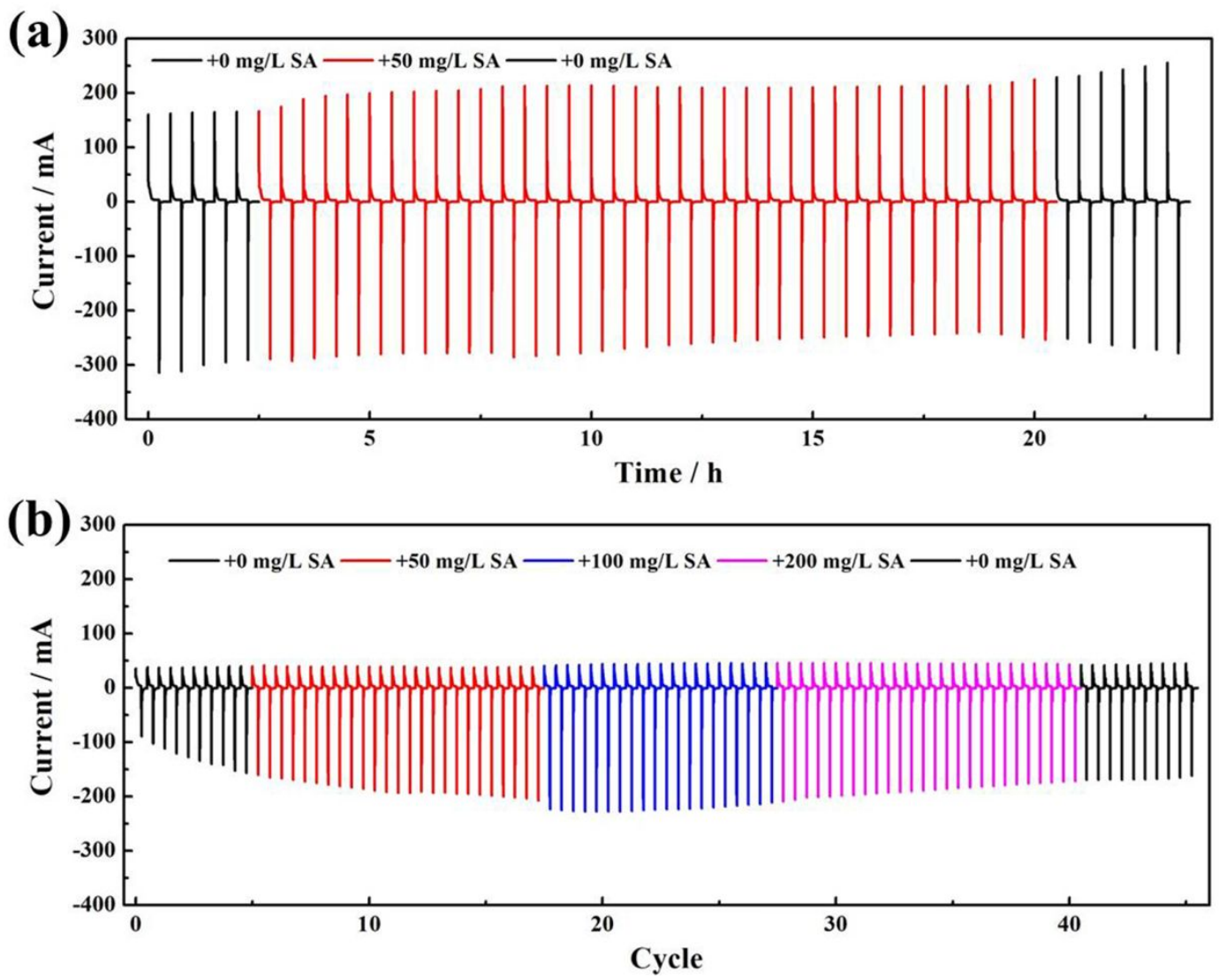

Figure S25. Charging and discharging currents of (a) the traditional CDI (bare) and (b) HT-MT-2 systems in $500 \mathrm{mg} \mathrm{L}^{-1} \mathrm{NaCl}$ with the addition of SA of $50-200 \mathrm{mg} \mathrm{L}^{-1}$. 


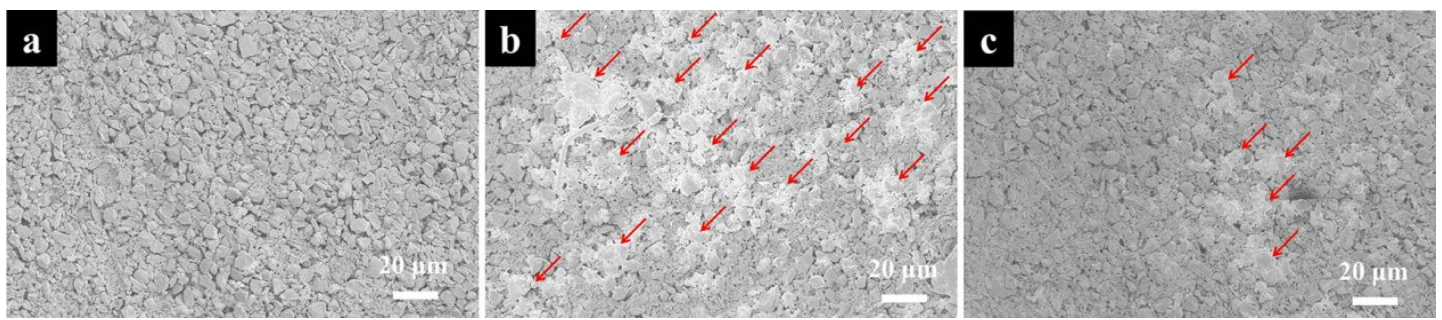

Figure S26. SEM analyses of (a) original AC electrode, (b) fouled AC anode, and (c) fouled AC cathode.
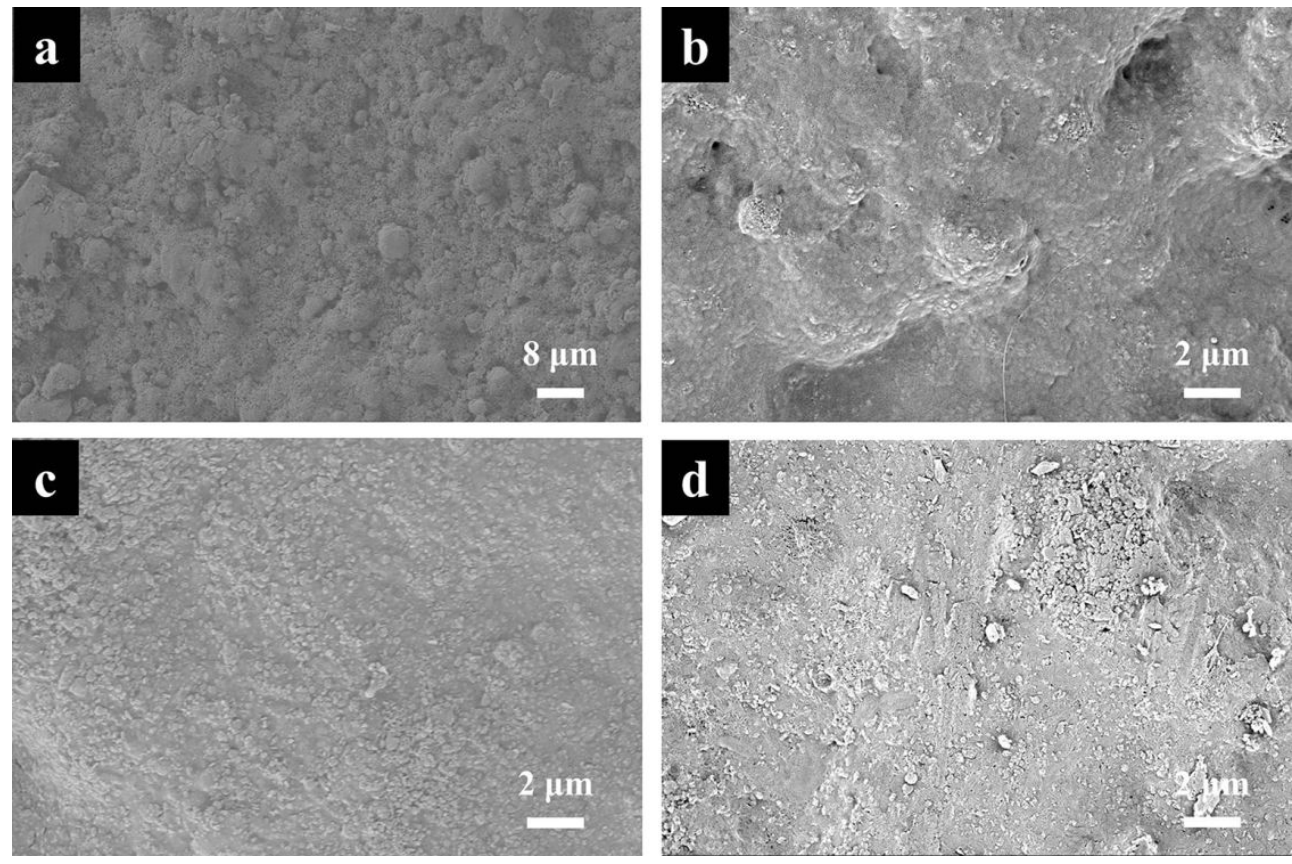

Figure S27. SEM analyses of fresh (a) MT-AC-3 and (c) HT-AC-2 electrodes, tested (b) MT-AC-3 and (d) HT-AC-2 electrodes. (MT-AC-3: mass ratio in MT coating is $3: 1$; HT-AC-2: mass ratio in HT coating is $5: 1$ ) 

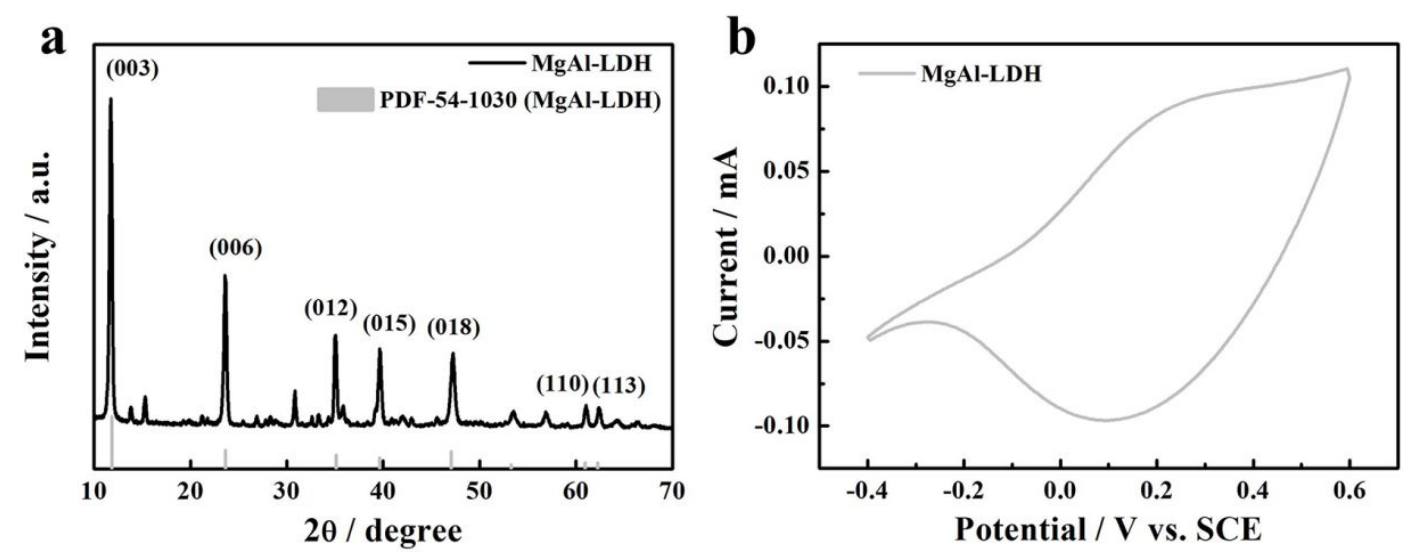

Figure S28. (a) XRD pattern of MgAl-LDH. (b) CV curve of MgAl-LDH-coated AC electrode.
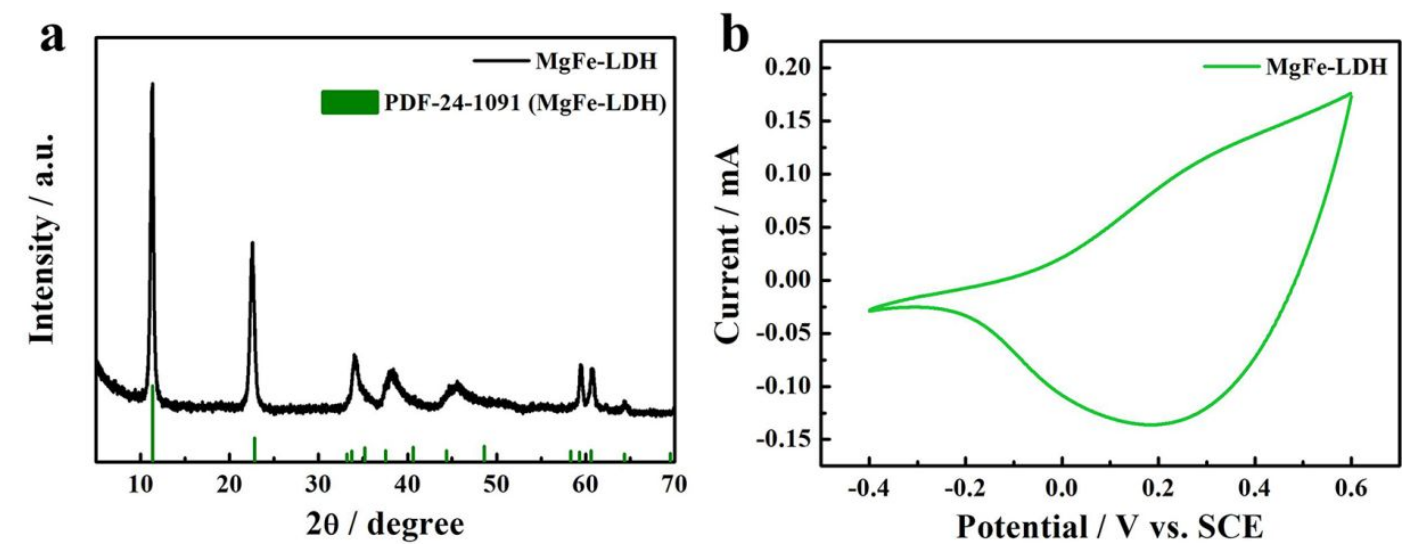

Figure S29. (a) XRD pattern of $\mathrm{MgFe}-\mathrm{LDH}$. (b) CV curve of $\mathrm{MgFe}-\mathrm{LDH}-$ coated $\mathrm{AC}$ electrode.
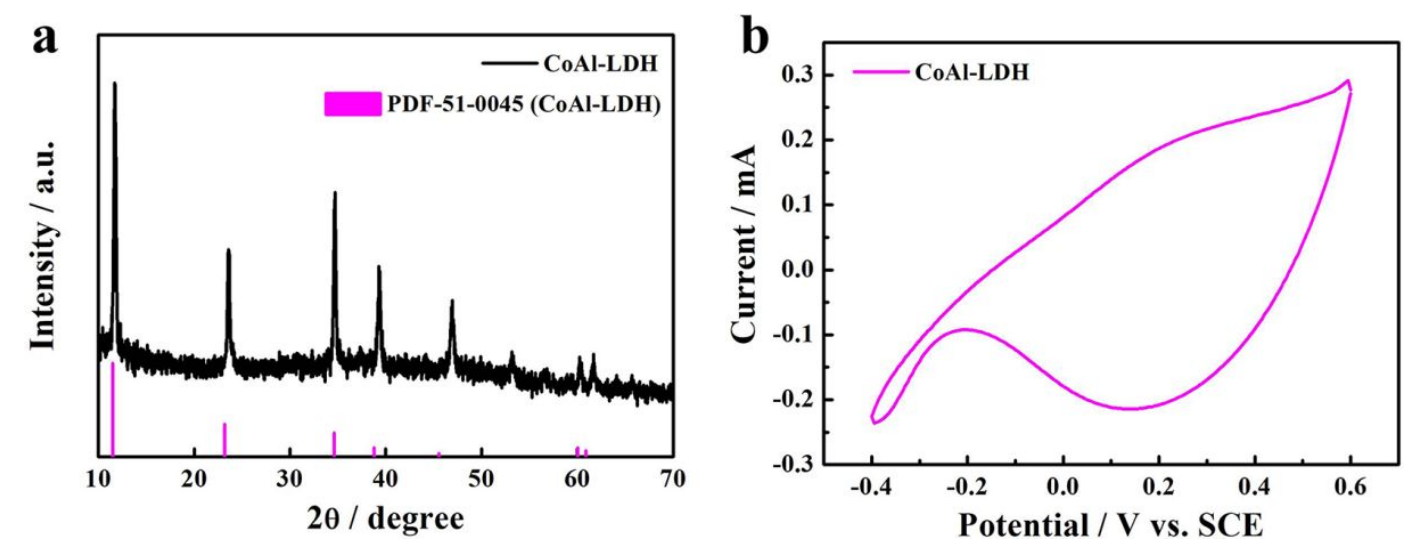

Figure S30. (a) XRD pattern of CoAl-LDH. (b) CV curve of CoAl-LDH-coated AC electrode. 

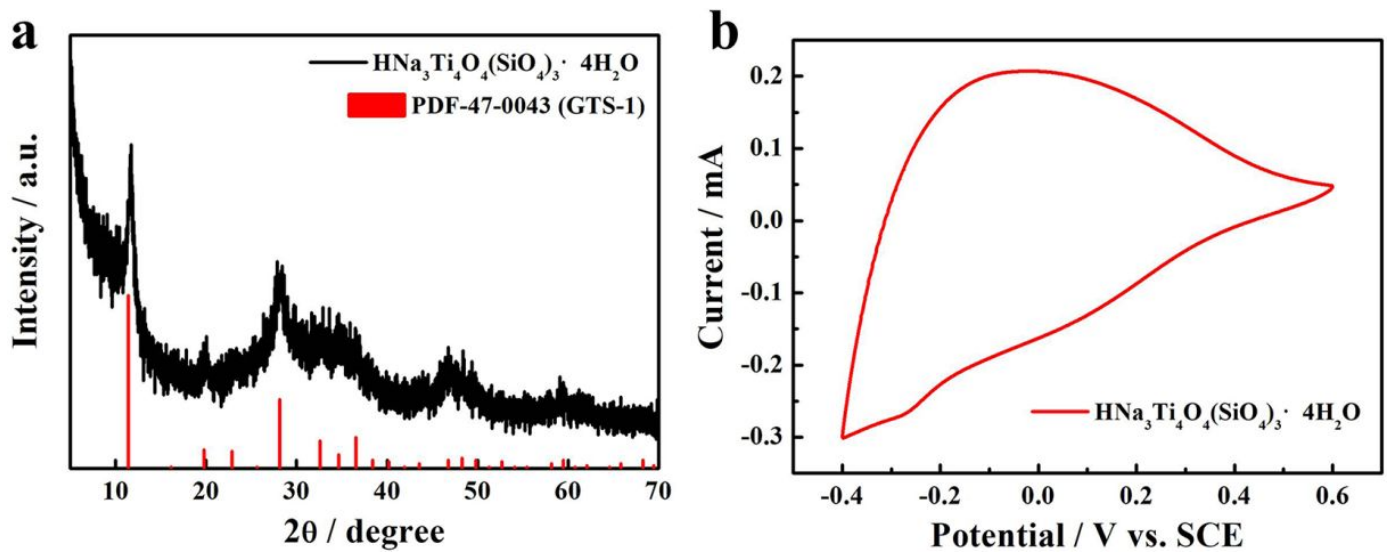

Figure S31. (a) XRD pattern of titanosilicate $\left(\mathrm{HNa}_{3} \mathrm{Ti}_{4} \mathrm{O}_{4}\left(\mathrm{SiO}_{4}\right)_{3} \cdot 4 \mathrm{H}_{2} \mathrm{O}\right)$. (b) $\mathrm{CV}$ curve of $\mathrm{HNa}_{3} \mathrm{Ti}_{4} \mathrm{O}_{4}\left(\mathrm{SiO}_{4}\right)_{3} \cdot 4 \mathrm{H}_{2} \mathrm{O}$-coated $\mathrm{AC}$ electrode.
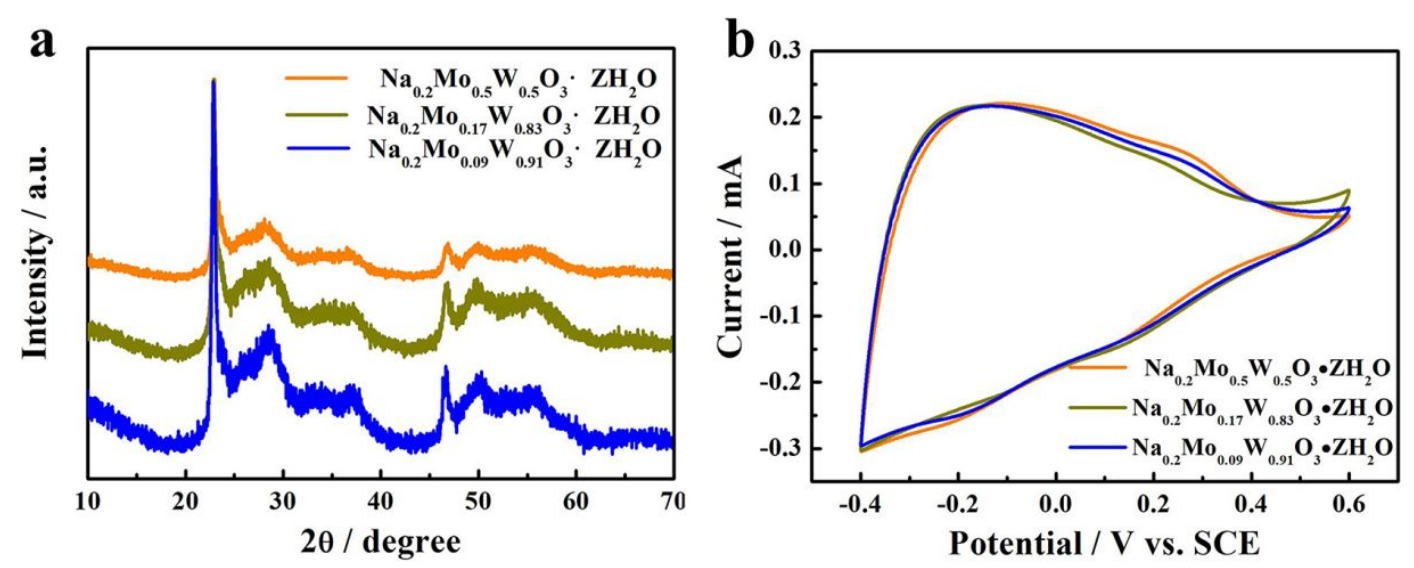

Figure S32. (a) XRD patterns of molybdenum-doped tungstates $\left(\mathrm{Na}_{0.2} \mathrm{Mo}_{\mathrm{y}} \mathrm{W}_{1-\mathrm{y}} \mathrm{O}_{3} \cdot \mathrm{ZH}_{2} \mathrm{O}\right)$. (b) $\mathrm{CV}$ curve of $\mathrm{Na}_{0.2} \mathrm{Mo}_{\mathrm{y}} \mathrm{W}_{1-\mathrm{y}} \mathrm{O}_{3} \cdot \mathrm{ZH}_{2} \mathrm{O}$-coated $\mathrm{AC}$ electrode. 